\title{
Research on Music Education Philosophical Aesthetic
}

\author{
Wenjuan Han \\ Weinan Normal University, Weinan, Shaanxi, 714000
}

Keywords: Music Education, Philosophical, Aesthetic

\begin{abstract}
Based on Aristotle's theory of practice, the practice of music education philosophy emphasizes that music is the practice of human diversity. Therefore, its theoretical basis is no longer a pure aesthetics, but a fusion of theories of various disciplines. In particular, from the perspective of musical anthropology, it is believed that the main task of music education is to enrich students 'musical experience. It is far more extensive than aesthetic experience and is associated with the students' experience in daily life.
\end{abstract}

\section{Introduction}

The emergence of the philosophy of practice music education has ended the philosophy of aesthetic music education as the only philosophical situation of music education. Meanwhile, it also expanded the space and vision of music and music education research and made the nature of music and music education more diversified. Interpretation is more prominent the importance and necessity of implementing multicultural music education. David. Elliot's book "Concerned about Music Practice" is a symbol of the emergence of the philosophy of music education. Aesthetic arts, unlike mechanical arts, are the art of direct intent, with delightful emotions, without purposeful intentional expressions of unintentional, ingenious features. Appreciation of aesthetic art is not limited to its form, but its content. The "Philosophy of Music Education" published by Bennett Raymer in 1970 is the pinnacle of the aesthetic education movement. It successfully expanded the flourishing aesthetic education movement in the 1950s and 1960s and also perfected the philosophy system of aesthetic music education. Different from other education, music education is not only a unique art itself, but also has a high aesthetic value. Aesthetic education embodies human emotions. According to Raymer, the essence and value of music education are premised on the nature and value of music. The philosophy of aesthetic music education emphasizes "music", that is, "aesthetic". Therefore, music education should center on the aesthetic quality of music. Melody, harmony, rhythm, intensity and so on all reflect the music value and uniqueness, therefore, the value of music lies in itself. Music education should cultivate aesthetic perception as the core, access to aesthetic experience, aesthetic sense and aesthetic response to play a role, we can get aesthetic experience. Aesthetic perception is a relatively complex combination of multiple behaviors, such as memory, association, discernment, etc., all of which can be changed under the influence of objective factors and can be taught. However, the aesthetic reaction is completely a subjective phenomenon. It has emotional reaction and cannot be imparted directly. This needs to be decided by the aesthetic quality of the thing itself. Therefore, students must be sensitive, accurate, enthusiastic perception, in order to make a sharp, accurate and enthusiastic response. Music education as an important role of aesthetic education is to be able to cultivate students' sensitivity to musical elements. Music chosen at different levels and different activities must be music with true expressiveness, and the most effective way for students to obtain auditory activities Aesthetic experience. The 1980s "The Philosophy of Music Education" (second edition) published, the second edition still retains the premise of the first edition of music education, aesthetic principles, etc., the difference is drawn from the theory of other disciplines of aesthetic philosophy deepen the promotion, and strengthen the emotional characteristics of aesthetic education. In a diversified social context, music is bound to develop in multiple ways. Different musical cultures bloom in different forms. In this kind of environment, the aesthetic quality of musical works cannot be influenced by utilitarian and purposeful values, which is also a problem to be solved urgently in 
aesthetic music education.

\section{Practice Music Education Philosophy}

Different from the interpretation of music by aesthetic philosophy education philosophy, practice philosophy of music education holds that "music is a kind of diversified human practice", which includes at least four actors as a result of certain action actions. territory. These four aspects are interdependent and interdependent. At the same time, music can be read at three different levels and refers to diverse human practices that embrace many different musical practices. Each musical practice includes two corresponding, mutually reinforcing activities for music production and music appreciation. At a lower level refers to the audible sound events, works, which come from the efforts of music actors in a concrete context of practice. Therefore, in practicing the philosophy of music education, music is more than sound, music practitioners, actions of practitioners, results, and the whole context of practice all influence the meaning of music. Its interpretation and analysis of music has not only limited to music structure and form itself, it fully affirmed the social, cultural and contextual dimensions of music. Therefore, the understanding of music is no longer limited to the understanding of skills and forms, music education must also consider such a change. Music is a diverse human practice, which is multicultural in nature, so it places particular emphasis on music production. Practice music education philosophy that music production in its unique way has a unique value, its value is to promote self-growth, self-awareness, the best experience of pleasure. In contrast, listening relies heavily on the cognitive aspects of the structural knowledge of music, the formal design, which is not the only part of music, and therefore not enough for a comprehensive understanding of music. The value of music appreciation is that it, as a concentrated form of thinking, makes sense in strengthening students' awareness and increasing their concentration. Since it is an activity centered on normative knowledge, it is self-contained. To fully develop students' musical literacy, they must develop their ability in music production and music appreciation so that they can gain self-awareness, self-growth and best experience in music activities. The music as a human practice, its value and the value of music education will inevitably require re-interpretation and evaluation.

If you want to lay a solid foundation for music education, you must accept the contemporary music culture. Contemporary music education also faces multiple challenges, not only internal and external. Each student's language, age, ethnic, family environment, musical ability, etc. are unique, music education should pay attention to the diversification of student culture. Teachers also embody different cultures, but teachers are the direct participants in education. Therefore, teachers should guide students with different cultural backgrounds to recognize the multiple reality and develop students who are good at developing themselves according to their own characteristics. Music is a multi-cultural convergence, it exists in the elegant culture and vulgar culture, mainstream culture and tributary culture, these cultures have the same effect on the practice of music education philosophy. In the practice of music education philosophy, the aesthetic experience in the aesthetic music education philosophy has been replaced by music experience. Students gain growth, cognition and pleasure in musical experience, which is in striking contrast with the concept of aesthetic music education. The practice of music education philosophy emphasizes multicultural music courses and redefines the interaction between people and music, which is the trend of the development of contemporary music education thoughts.

\section{Aesthetic Music Education Philosophy and Practice Music Education Philosophy}

Music is a diverse human activity that is based on society and is therefore borderless. The formation and development of aesthetic paradigm and practice paradigm are closely related to the social, cultural and educational environments, all of which have their unique characteristics and historical significance. The aesthetic philosophy of music education challenges are from its own philosophical foundation. At present, the philosophy of music education is moving towards internationalization and diversification in the context of the continuous development of society. 
There must be a broad future in the study of music education philosophy. Both aesthetic philosophy of music education and practice of philosophy of music education have an irreplaceable historical role, however, both philosophy of music education also has its own shortcomings. The philosophy of aesthetic music education regards music as an aesthetic object, and Remer advocates the consistency of the aesthetic valuesof music. People can also improve their aesthetic ability through hearing. This has led to the aesthetic philosophy of music education denying music works and history, and society must have The association. Aesthetic music that music has an "unspoken" trait, it is not cultural and contextual constraints. However, in the third edition of "Philosophy of Music Education", Raymer proposed that the social context factors have some influence on music comprehension, but the influence is negligible and not obvious. This "unspoken" trait makes music have the cultural, political implications, this modern trait has been questioned by postmodernism. Aesthetic experience breaks away from everyday experience, but artistic experience itself is closely linked with life because music exists in public life and lives in harmony. Music activities cannot be separated from all daily life experience, we cannot put music and art experience in an isolated position, even given it noble color, which is the misunderstanding of the essence of life experience. The aesthetic concept relies on the theory of binary cognition. The aesthetic music education philosophy embodies the musical philosophy and culture under the European elite culture and modern philosophy. Under this philosophical theory, all music is the expression of human emotions, and also determines Music education must be aesthetic education, people in the aesthetic education constantly cultivate cognitive ability and aesthetic experience. However, this kind of music philosophy does not adapt to the diversified development of society. There are still many problems in the philosophy of aesthetic music education, which are inextricably linked with the theoretical basis of its construction. Compared with the philosophy of aesthetic music education, the practice of music education philosophy has a positive meaning, which opens up another philosophy for music education. The practice of music education emphasizes the multidimensionality and comprehensiveness of music and attaches importance to the influence of music, culture, society and context, breaking the bondage of the dualistic opposites of traditional music education philosophy and emphasizing the importance of multicultural music education. However, because of the time relationship, the philosophy of practice music education has not been further improved. Starting from the system construction, the practice of music education philosophy faces many challenges. Practice music education philosophy emphasizes the diversification of music, ignoring the subjectivity of local culture. At the same time, the practice of philosophy of music education is also a relatively new theoretical thought. Without going through a long period of experience, more practical research needs to be done in order to exert its true practical benefits.

\section{Conclusions}

The decisions and actions of music educators are always influenced by certain philosophical concepts. Different times and cultures determine the diversity of music education philosophy. Whether we are inclined to that kind of concept, aesthetic or functional, in fact, music education plays a non-negligible role in the development of people and society. The music education in our country began to pay attention to the value of aesthetic education as the core of music education after all the services for politics and professionalism in the 1990s before 1980s. However, we should also see the multifaceted and holistic value of music and the connection between music life and social life. Must not be isolated and closed only talk about aesthetic, ignoring the other functions of music education. We must dialectically treat the ontological and non-self-worth of music education. We must not over-emphasize one's side and create the extreme of understanding and action. Only when we clear our thinking from the ideas can we develop healthily in concrete practice.

\section{Acknowledgements}

Fund Project: Shaanxi Provincial Department of Education research project: "promote the red 
spirit and cultivate entrepreneurship scientific talent research" (16JK1251); Shaanxi Province, "12th Five-Year Plan" of Education Science project 2014 "primary and secondary school teachers in the perspective of economics professional ethics Research "(SGH140758)

\section{References}

[1] Han Zhongling. On the value of music education philosophy [J]. Yellow River Voice. 2012 (02)

[2] Xiong Jiaying. The development of music education philosophy and its impact on music education in China [J]. New Campus (early). 2017 (10)

[3] Li Ling. The practice of music education philosophy research [J]. People's Music. 2016 (11)

[4] Feng Doli. Analysis of Thanksgiving education paradigm based on the philosophy of music education [J]. Higher Education Press. 2017 (07)

[5] Chang Yan, Zhang Xiaodan, Sheng Haiming. Practice music education philosophy and music education curriculum reform [J]. Education Theory and Practice. 2017 (15)

[6] Yang Sisi. From Rorty to Bowman: New pragmatism of musical education philosophy [J]. Beauty and the Times (next). 2017 (05) 